\title{
INQUÉRITO SORO-EPIDEMIOLÓGICO DE BRUCELLA OVIS EM REBANHOS OVINOS NO SEMIÁRIDO BAIANO
}

\author{
T.S. Souza ${ }^{1 *}$, J.N. Costa ${ }^{2}$, P.M. Martinez ${ }^{3}$, C.C.V. Lima ${ }^{1 * *}$, B.R. Araújo ${ }^{1 * *}$, \\ A.O. Costa Neto ${ }^{4}$, A.V.M. Anunciação ${ }^{5}$, M.G.A.R. Almeida ${ }^{5}$, R.R. Pinheiro ${ }^{6}$ \\ ${ }^{1}$ Universidade Federal da Bahia, Escola de Medicina Veterinária e Zootecnia, Av. Adhemar de Barros, 500, \\ CEP 40.170-110, Salvador, BA, Brasil. E-mail: thiago_sampaio@hotmail.com
}

\section{RESUMO}

\begin{abstract}
Com o objetivo de analisar a ocorrência de anticorpos contra Brucella ovis em ovinos no semiárido baiano, este inquérito foi conduzido em rebanhos da microrregião de Juazeiro, Bahia. O teste de imunodifusão em gel de ágar (IDGA) foi utilizado para examinar 694 amostras de soro de 58 rebanhos. Anticorpos para B. ovis foram observados em cinco $(0,72 \%)$ dos animais investigados. Acredita-se que o baixo número de soropositivos deva-se às características dos sistemas de produção, com predominância do tipo de exploração extensiva de animais localmente adaptados, mestiços e sem raça definida para a produção de carne e pele, com baixa produtividade e tecnificação.
\end{abstract}

PALAVRAS-CHAVE: Brucelose ovina, epidemiologia, IDGA, ocorrência.

\section{ABSTRACT}

SERO-EPIDEMIOLOGICALSURVEY FOR BRUCELLA OVIS INFECTION INSHEEP FLOCKS OF BAHIA STATE, BRAZIL. In order to analyze the occurrence of antibodies to Brucella ovis in sheep in a semi-arid region, this survey was conducted in the micro-region of Juazeiro, Bahia State, Brazil. The agar gel immunodifusion test (AGID) was used to examine 694 serum samples of 58 flocks. Antibodies to B. ovis were found in $5(0.72 \%)$ of the investigated animals. It is believed that this low number of positive cases is related to the characteristics of the production. The predominant system is the extensive one, with presence of locally adapted breeds and crossbred animals, aiming at the production of meat and skin, with low productivity rates and technical development.

KEY WORDS: AGID, epidemiology, occurrence, ovine brucellosis.

A Brucella ovis tem despertado grande interesse devido ao aumento da criação de ovinos em todo o mundo e ao conhecimento sobre a sua disseminação nos rebanhos (LIRA; MEGID, 2009). É um microorganismo que desencadeia doença crônica e possui distribuição mundial, causando grande impacto negativo nos países onde a ovinocultura é uma atividade econômica importante (FICAPAL et al., 1998; Robles et al., 1998; EsTEIN, 1999; QUISPE et al., 2002).

A enfermidadecaracteriza-se por epididimitenos machos, abortamento nas fêmeas, ocorrência de natimortos, nascimento de cordeiros fracos e aumento da mortalidade perinatal, provocando a diminuição da eficiência reprodutiva dos rebanhos (LIBAL; KIRKBRIDE, 1983; Magalhães Neto; GIL-Turnes, 1996).

Inquéritos sorológicos realizados no Brasil demonstraram resultados diversos, com algumas regiões apresentando maiores frequências de animais positivos, como no Rio Grande do Norte, 35,5\% (Silva et al., 2003); em Pernambuco, 17,5\% (Coleto et al., 2003) e no Rio Grande do Sul, 13,4\% (MAGALHÃES NeTO; GIL-Turnes, 1996) e outras com ocorrência mais baixa ou nula, como na Paraíba, 5,57\% (CLEMENTINO et al., 2007); na Bahia, 3,27\% (SILVA et al., 2009); em

\footnotetext{
${ }^{2}$ Universidade Federal da Bahia, Escola de Medicina Veterinária e Zootecnia, Departamento de Patologia e Clínicas, Salvador, BA, Brasil.

${ }^{3}$ Companhia de Desenvolvimento dos Vales do São Francisco e Parnaíba, 6a SR, Juazeiro, BA, Brasil.

${ }^{4}$ Universidade Estadual de Feira de Santana, Departamento de Biologia, Feira de Santana, BA, Brasil.

${ }^{5}$ Universidade Federal da Bahia, Escola de Medicina Veterinária e Zootecnia, Hospital de Medicina Veterinária, Laboratório de Viroses, Salvador, BA, Brasil.

${ }^{6}$ Empresa Brasileira de Pesquisa Agropecuária, Embrapa Caprinos e Ovinos, Sobral, CE, Brasil.

*Programa de Pós-Graduação em Ciência Animal nos Trópicos, Bolsista de doutorado da FAPESB.

**Programa de Pós-Graduação em Ciência Animal nos Trópicos.
} 
Alagoas, 3,1\% (PinHeIroJunioretal., 2009); São Paulo, 0\% (Marinho; Mathias, 1996) e 1,96\% (Rizzo et al., 2009) e em Santa Catarina, 0\% (SCHÄFER et al., 1997). A B. ovis já foi isolada no nordeste brasileiro (Alves et al., 2010).

Considerando as perspectivas de crescimento da ovinocultura e a necessidade de informações acerca da ocorrência de doenças, este trabalho teve por objetivo a condução de inquérito soro-epidemiológico da B. ovis na microrregião de Juazeiro, Bahia.

Esta região localiza-se na parte setentrional do estado e é constituída por oito municípios: Juazeiro, Sobradinho, Curaçá, Casa Nova, Campo Alegre de Lourdes, Pilão Arcado, Remanso e Sento Sé (BAHIA, 2009). Dentre as suas principais características, destacam-se o clima semiárido, a presença do RioSão Francisco e do Lago de Sobradinho, a agricultura irrigada e o Polo Agroindustrial de Petrolina-Juazeiro, produtor e exportador de frutas. Além disso, essa região possui uma das maiores concentrações de ovinos do país, com 614.782 ovinos, o equivalente a, aproximadamente, $23 \%$ do rebanho baiano e $4,3 \%$ do rebanho nacional, de acordo com o Censo Agropecuário de 2006 (IBGE, 2010).

O tamanho aproximado da amostra foi calculado segundo THRusfield (2004), com nível de confiança de $95 \%$ e precisão de $5 \%$. Como a prevalência estimada não era conhecida, utilizou-se no cálculo a prevalência esperada de $50 \%$, a fim de maximizar o tamanho da amostra, que foi de 384 . Entretanto, foram analisadas 694 amostras oriundas de 58 rebanhos selecionados por método não probabilístico, já que não havia listas de propriedades rurais que possibilitassem a amostragem aleatória.

As colheitas foram distribuídas entre os oito municípios que compõem a microrregião de Juazeiro, proporcionalmente a participação de cada um deles no rebanho total, levando-se em consideração os dados relativos à pecuária divulgados pelo Instituto Brasileiro de Geografia e Estatística (IBGE), em 2007.

As propriedades visitadas foram cadastradas e os animais que participaram da pesquisa foram registrados com brincos numerados quando permitido pelo proprietário. Além disso, aplicou-se um questionário visando à caracterização dos sistemas de criação. A partir dessas informações, calcularam-se intervalos de confiança para proporção, considerando que este é um estudo observacional (MARTINS, 2006).

A idade dos animais foi estimada com base na arcada dentária, sendo utilizados aqueles com mais de seis meses de idade. Realizou-se a colheita de sangue após antissepsia adequada, através da venopunção da jugular, utilizando-setubos a vácuo. Emseguida, após a formação de coágulo, os tubos foram centrifugados a $1.500 \mathrm{~g}$ por 10 minutos para a obtenção dos soros, que foram acondicionados em microtubos tipo eppendorf, identificados e estocados a $-20^{\circ} \mathrm{C}$.

A sorologia para detecção de anticorpos anti- $B$. ovis foi realizada pelo método de imunodifusão em gel de ágar (IDGA), utilizando-se kits produzidos pelo Instituto de Tecnologia do Paraná (TECPAR). O antígeno consiste de proteínas e lipopolissacarídeos solúveis, extraídos da bactéria B. ovis, amostra Reo 198. A metodologia foi conduzida baseando-se nas recomendações do fabricante.

Do total de 694 amostras testadas pertencentes a 58 propriedades, observou-se $0,72 \%(0,09-1,35 \%$; IC: 95\%) de animais apresentando anticorpos contra $B$. ovis e $8,62 \%(1,40-15,84 \%$; IC: $95 \%)$ de propriedades com animal soropositivo (Tabela 1).

Neste estudo, 89,6\% (81,74-97,46\%; IC: 95\%) das propriedades visitadas adotavam sistema extensivo de criação; 10,4\% (2,54 - 18,26\%; IC: 95\%) o sistema semi-intensivo e não foi observada propriedade com o sistema intensivo. As propriedades que apresentaram animal soropositivo possuíam criação extensiva.

Magalhães Neto; Gil-Turnes (1996) verificaram maior soropositividade para $B$. ovis em animais mantidos em regime de cabanha, justificando este dado aos fatores de manejo, como maior concentração em espaços reduzidos. Já PINHEIRO Junior et al. (2009) verificaram maior soropositividade em sistemas extensivos e CLEMENTINo et al. (2007) não observaram diferença significativa entre os animais criados de forma extensiva e os de forma intensiva/ semi-intensiva, apesar de a odds ratio ter demonstrado que os animais do sistema extensivo possuíram duas vezes mais risco de contraírem a infecção.

Tabela 1 - Frequência de amostras e propriedades positivas para Brucella ovis na microrregião de Juazeiro, Bahia.

\begin{tabular}{|c|c|c|c|c|}
\hline Município & $\begin{array}{l}\mathrm{N}^{\mathrm{o}} \text { de amostras } \\
\text { colhidas }\end{array}$ & $\begin{array}{c}\text { Frequência de } \\
\text { animais positivos (\%) }\end{array}$ & $\begin{array}{c}\mathrm{N}^{o} \text { de propriedades } \\
\text { pesquisadas }\end{array}$ & $\begin{array}{c}\text { Frequência de } \\
\text { propriedades positivas }(\%)\end{array}$ \\
\hline Juazeiro & 156 & 0 & 13 & 0 \\
\hline Sobradinho & 10 & 0 & 1 & 0 \\
\hline Curaçá & 72 & 0 & 6 & 0 \\
\hline Casa Nova & 120 & 0 & 10 & 0 \\
\hline Campo Alegre de Lourdes & 60 & 1,67 & 5 & 20 \\
\hline Pilão Arcado & 60 & 1,67 & 5 & 20 \\
\hline Remanso & 168 & 1,19 & 14 & 14,29 \\
\hline Sento Sé & 48 & 2,08 & 4 & 25 \\
\hline Total & 694 & 0,72 & 58 & 8,62 \\
\hline
\end{tabular}


Na microrregião de Juazeiro, apesar da predominância de sistemas extensivos, a prevalência observada foi baixa. Por isso, acredita-se que o tipo de sistema não pode ser analisado como fator predisponente de forma isolada. Na Espanha, por exemplo, Ficapal et al. (1998) não observaram diferença estatística de soropositividade entre rebanhos pequenos ou médios e grandes. Isto pode ser explicado, segundo os autores, em parte pelo fato de os proprietários dos grandes rebanhos possuírem maior nível técnico e melhores práticas de manejo.

Por outro lado, isso não se aplica aos rebanhos estudados, pois, independentemente do tamanho, observou-se baixa qualidade técnica nas práticas de criação. Apenas 41,4\% (28,72 - 54,08\%; IC: $95 \%)$ das propriedades possuíam acompanhamento técnico que era, em sua maior parte, realizado de forma irregular por programa estadual que foi desativado. Procedimento profilático básico, como a cura do umbigo de recém-nascidos com a tintura de iodo, só foi observado em 12,1\% (3,71 - 20,49\%; IC: $95 \%)$ dos rebanhos visitados.

Quando se analisa a ocorrência de anticorpos anti-B. ovis observa-se que em propriedades onde há assistência veterinária para avaliação frequente dos animais e cuidados higiênico-sanitários, a ocorrência de soropositivos é menor ou nula. Já em criações para subsistência e decria/recria/engorda, espera-se que a frequência de soropositivos seja maior devido à deficiência do manejo do rebanho (CLEMENTINO et al., 2007).

Na região de estudo, existe um sistema extensivo decriação conhecidocomo "fundo de pasto", ondeas propriedades não são registradas, não existe divisão de pastagens, são áreas comuns onde os animais de vários proprietários são criados de forma coletiva (SouzA et al., 2010). Levando-se em consideração essas características, verifica-se que a $B$. ovis possui condições favoráveis de disseminação nesses rebanhos. Entretanto, os resultados sorológicos não refletiram essa tendência e isso pode ser justificado quando outros fatores são analisados.

A maior parte dos animais que constituíam os rebanhos tinha origem local. Apenas em 6,9\% (0,38 -13,42\%; IC: $95 \%$ ) das propriedades observaram-se animais com origem em outros estados e/ou países. Além disso, a maioria dos rebanhos possuía animais de raças localmente adaptadas como Santa Inês, Morada Nova e Rabo Largo, mestiços e sem raça definida (SRD), sendo que apenas 19\% (8,9 - 29,1\%; IC: $95 \%)$ das propriedades visitadas possuíam animais de raças importadas, como a Dorper. Segundo FICAPAL et al. (1998), maiores soropositividades são observadas em animais de raças importadas, quando comparados com os de raças locais.

A ocorrência de B. ovis está historicamente relacionada com a importação de animais infectados. $\mathrm{O}$ primeiro isolamento de B. ovis no Brasil foi realizado no Rio Grande do Sul, após notificações de elevada mortalidade de cordeiros, ocorrência de natimortos, abortamentos e epididimite nos machos, associados à entrada de animais oriundos de países nos quais a doença já tinha sido diagnosticada (RAmos et al., 1966; Blobel et al., 1972).

A introdução de outros agentes infecciosos, como os lentivírus de pequenos ruminantes (PINHEIRO et al., 2001; MARTinez et al., 2011) e o vírus da língua azul (Melo et al., 2000; SouzA et al., 2010), em áreas livres também está relacionada com a importação e intenso trânsito de animais, principalmente visando ao melhoramento genético, entretanto, sem os devidos cuidados, como realização de exames para prevenção de novas enfermidades.

$\mathrm{Na}$ microrregião de Juazeiro, a maior parte das propriedades pesquisadas possuía o tipo de exploração para corte e pele, $93,1 \%$ (86,6 - 99,6\%; IC: $95 \%$ ), e o trânsito de animais ocorria mais em função da comercialização visando ao abate e não ao melhoramento genético com a introdução de raças importadas. Isso pode explicar a baixa soropositividade observada para B. ovis nesses rebanhos, apesar de não haver o controle do trânsito de ovinos com base neste agente infeccioso.

Dos cinco animais soropositivos, quatro eram fêmeas e um era macho. Quanto à faixa etária, dois possuíam entre um e três anos deidade e três animais soropositivos tinham mais de três anos. Segundo RoBLEs et al. (1998), a epididimite por B. ovis é uma enfermidade principalmente de carneiros adultos com experiência sexual prévia. Animais muito jovens, com pouca experiência sexual ou animais mais velhos, com atividade sexual diminuída, são menos expostos à infecção (FICAPAL et al., 1998).

No que diz respeito à apresentação de sinais clínicos da epididimite ovina nos rebanhos estudados, como as amostras testadas foram oriundas de levantamento epidemiológico para lentivírus de pequenos ruminantes (MARTINEZ et al., 2011) e vírus da língua azul (SouzA et al., 2010), não foi realizado exame específico do aparelho genital. No entanto, em outros inquéritos epidemiológicos conduzidos no Brasil, apesar da observação de animais soropositivos para $B$. ovis ao teste de IDGA, sinais clínicos não foram verificados (Coleto et al., 2003; AzEvedo et al., 2004; NozAKI et al., 2004; PINHeIro Junior et al., 2009; SiLva et al., 2009).

O diagnóstico da brucelose ovina se realiza geralmente através de provas sorológicas, sendo as mais utilizadas as de fixação de complemento (FC), IDGA e ensaio imunoenzimático (ELISA) (ROBLES, 1998). Estudos comparativos demonstraram que o teste deELISA é mais sensível (97,6\%) que o de IDGA $(96,4 \%)$ e o deFC $(92,7 \%)$. Os três testes apresentaram especificidade de $100 \%$ (MARÍN et al., 1989). Robles 
(1998) também verificou especificidade de 100\% e sensibilidade de $97,10 \%$ para o teste de IDGA, quando animais naturalmente infectados foram avaliados.

Levando-se em consideração os resultados expostos, foi possível verificar que a frequência de animais soropositivos para $B$. ovis na microrregião de Juazeiro foi baixa, possivelmente devido ao modo de criação predominante na região, que minimizou as possibilidades de introdução do agente e não pela adoção de medidas de prevenção.

\section{REFERÊNCIAS}

ALVES, C.J.; FIGUEIREDO, S.M.; AZEVEDO, S.S.; CLEMENTINO, I.J.; KEID, L.B.; VASCONCELLOS, S.A.; BATISTA, C.S.A.; ROCHA, V.C.M.; HIGINO, S.S. Detection of Brucella ovis in ovine from Paraíba State, in the Northeast Region of Brazil. Brazilian Journal of Microbiology, v.41, p.365-367, 2010.

\section{AZEVEDO, S.S.; ALVES, C.J.; ALVES, F.A.L.; CLE-} MENTINO, I.J.; BATISTA, C.S.A.; AZEVEDO, A.S. Ocorrência de anticorpos anti-Brucella ovis em ovinos procedentes de quatro municípios do estado do Rio Grande do Norte, Brasil. Agropecuária Técnica, v.25, n.2, p.45-50, 2004.

BAHIA. Superintendência de Estudos Econômicos e Sociais da Bahia. Região Econômica baixo médio São Francisco - Estado da Bahia. Disponível em: <http:/ / www.sei.ba.gov.br/site/geoambientais/cartogramas/ regioes_eco/pdf/regecon_bax_medio_sf.pdf $>$. Acesso em: 4 ago. 2009.

BLOBEL, H.; FERNANDES, J.C.T.; MIES FILHO, A.; RAMOS, A.A.; TREIN, E.J. Estudos sobre a etiologia da epididimite ovina no Rio Grande do Sul. Pesquisa Agropecuária Brasileira, v.7, p.1-4, 1972.

CLEMENTINO, I.J.; ALVES, C.J.; AZEVEDO, S.S.; PAULIN, L.M.; MEDEIROS, K.A. Inquérito soro-epidemiológico e fatores de risco associados à infecção por Brucella ovis em carneiros deslanados do semi-árido da Paraíba. Pesquisa Veterinária Brasileira, v.27, n.4, p.137-143, 2007.

COLETO, Z.F.; PINHEIRO JUNIOR, J.W.; MOTA, R.A.; GUERRA, M.M.P.; SIMPLÍCIO, K.M.M.G.; CÂMARA, D.R.; SOARES, R.P.T.; PORTO, W.J.N.; CINTRA JUNIOR, J.E.; FAUSTINO, M.G.; SOUZA, A.F.; BERTO, R.S. Ocorrência de infecção por Brucella ovis em ovinos do Estado de Pernambuco e sua participação em distúrbios reprodutivos nesta espécie (estudos preliminares). Revista Brasileira de Reprodução Animal, v.27, n.3, p.551552, 2003.

ESTEIN, S.M. Aspectos inmunológicos en el diagnóstico y control de la epidemitis contagiosa del carnero por Brucella ovis. Archivos de Medicina Veterinaria, v.31, n.1, p.5-17, 1999.
FICAPAL, A.; JORDANA, J.; BLASCO, J.M.; MORIYÓN, I. Diagnosis and epidemiology of Brucella ovis infection in rams. Small Ruminant Research, v.29, p.13-19, 1998.

IBGE. INSTITUTO BRASILEIRO DE GEOGRAFIA E ESTATÍSTICA. Pecuária - Rebanho ovino. Disponível em: <http:// www.ibge.gov.br> Acesso em: 24 fev. 2007.

IBGE. INSTITUTO BRASILEIRO DE GEOGRAFIA E ESTATÍSTICA. Censo Agropecuário 2006 - Rebanho ovino. Disponível em:<http://www.ibge.gov.br> Acesso em: 22 abr. 2010.

LIBAL, M.C.; KIRKBRIDE, C.A. Brucella ovis-induced abortion in ewes. Journal of the American Veterinary Medical Association, v.183, n.5, p.553-554, 1983.

LIRA, N.S.C.; MEGID, J. Patogenia da brucelose ovina. Veterinária e Zootecnia, v.16, n.2, p.280-289, 2009.

MAGALHÃES NETO, A.; GIL-TURNES, C. Brucelose ovina no Rio Grande do Sul. Pesquisa Veterinária Brasileira, v.16, n.2/3, p.75-79, 1996.

MARÍN, C.M.; JIMÉNEZ DE BAGUÉS, M.P.; BLASCO, J.M.; GAMAZO, C.; MORIYÓN, I.; DÍAZ, R. Comparison of three serological tests for Brucella ovis infection of rams using different antigenic extracts. The Veterinary Record, v.125, p.504-508, 1989.

MARINHO, M.; MATHIAS, L.A. Pesquisa de anticorpos contra Brucella ovis em ovinos do estado de São Paulo. Pesquisa Veterinária Brasileira, v.16, n.2/3, p.45-48, 1996.

MARTINEZ, P.M.; COSTA, J.N.; SOUZA, T.S.; LIMA, C.C.V.; COSTA NETO, A.O.; PINHEIRO, R.R. Prevalência sorológica da maedi-visna em rebanhos ovinos da Microrregião de Juazeiro - Bahia por meio do teste de imunodifusão em gel de ágar. Ciência Animal Brasileira, v.12, n.2, p.322-329, 2011.

MARTINS, G.A. Estatística geral e aplicada. 3.ed. São Paulo: Atlas, 2006. 428p.

MELO, C.B.; OLIVEIRA, A.M.; AZEVEDO, E.O.; LOBATO, Z.I.P.; LEITE, R.C. Anticorpos contra o vírus da língua azul em bovinos do sertão da Paraíba. Arquivo Brasileiro de Medicina Veterinária e Zootecnia, v.52, n.1, p.19-20, 2000.

NOZAKI, C.N.; MEGID, J.; LIMA, K.C.; SILVA JUNIOR, F.F.; VELOSO, C.S. Comparação das técnicas de imunodifusão em gel de ágar e ELISA no diagnóstico de brucelose ovina em cabanhas da região centro-oeste do estado de São Paulo. Arquivos do Instituto Biológico, São Paulo, v.71, n.1, p.1-5, 2004.

PINHEIRO, R.R.; GOUVEIA, A.M.G.; ALVES, F.S.F. Prevalência da infecção pelo vírus da Artrite-Encefalite Caprina no Estado do Ceará, Brasil. Ciência Rural, v.31, n.3, p.449-454, 2001. 
PINHEIRO JUNIOR, J.W.; OLIVEIRA, A.A.F.; MOTA, R.A.; AGOTTANI, J.V.; JESUS, E.M.; ASSIS, S.T.; OLIVEIRA, C.Z. Ocorrência de ovinos sororeatores para Brucella ovis no estado de Alagoas, Brasil. Veterinária e Zootecnia, v.16, n.3, p.500-508, 2009.

QUISPE, R.C.; RIVERA, H.G.; ROSADIO, R.A. Cinética de la infección por Brucella ovis en carneros durante una época de empadre. Revista de Investigatión Veterinaria de Peru, v.13, n.1, p.61-66, 2002.

RAMOS, A.A.; MIES FILHO, A.; SCHENCK, J.A.P.; VASCONCELLOS, L.D.; PRADO, O.T.G.; FERNANDES, J.C.T.; BLOBEL, H. Epididimite ovina. Levantamento clínico no Rio Grande do Sul. Pesquisa Agropecuária Brasileira, v.1, p.211-213, 1966.

RIZZO, H.; GREGORY, L.; PINHEIRO, E.S.; CARVALHO, A.F.; SANTANA, R.L.; SILVA, L.M.P. Incidência de Brucella ovis em ovinos com histórico de distúrbios reprodutivos no estado de São Paulo, Brasil. Ciência Animal Brasileira, p.591-596, 2009. Trabalho apresentado no CONGRESSO BRASILEIRO DE BUIATRIA, 8., 2009, Belo Horizonte. Disponível em: <http:/ / www.revistas. ufg.br/index.php/vet/article/view/7864/5684>. Acesso em: 5 set. 2010.

ROBLES, C.A. Evaluación de una técnica de doble difusión en gel de agar para el diagnostico de la infección por Brucella ovis en carneros. Veterinaria Argentina, v.15, n.142, p.119-125, 1998.

ROBLES, C.A.; UZAL, F.A.; OLAECHEA, F.V.; LOW, C. Epidemiological observations in a Corriedale flock affected by Brucella ovis. Veterinary Research Communications, v.22, n.7, p.435-443, 1998.

SCHÄFER, I.; VAZ, A.; RAMELLA, J.; COUTINHO, G. Prevalência de carneiros reagentes à prova de imunodifusão em gel para Brucella ovis no município de Lages-SC. A Hora Veterinária, v.17, n.99, p.60-61, 1997.

SILVA, J.B.A.; FEIJO, F.M.C.; TEIXEIRA, M.F.S.; SILVA, J.S. Prevalência de brucelose ovina causada por Brucella ovis em rebanhos do estado do Rio Grande do Norte, Brasil. Ciência Animal, v.13, n.1, p.51-54, 2003.

SILVA, N.S.; BARROS, I.N.; DASSO, M.G.; ALMEIDA, M.G.A.R.; LABORDA, S.S.; ANUNCIAÇÃO, A.V.M.; MOREIRA, E.L.T.; LIMA-SILVA, A.E.; OLIVEIRA, E.M.D. Detecção de anticorpos anti-Brucella ovis em ovinos do estado da Bahia. Revista Brasileira de Saúde e Produção Animal, v.10, n.4, p.852-859, 2009.

SOUZA, T.S.; COSTA, J.N.; MARTINEZ, P.M.; COSTA NETO, A.O.; PINHEIRO, R.R. Anticorpos contra o vírus da língua azul em rebanhos ovinos da Microrregião de Juazeiro, Bahia. Arquivos do Instituto Biológico, São Paulo, v.77, n.3, p.419-427, 2010.

THRUSFIELD, M.V. Inquéritos. In: (Ed.). Epidemiologia veterinária. 2.ed. São Paulo: Roca, 2004. p.223-247.

Recebido em 23/2/11

Aceito em 2/5/12 